\title{
Polymerase chain reaction for detection of Toxoplasma gondii
}

\author{
D. SAVVA, J. C. MORRIS, J. D. JOHNSON* and R. E. HOLLIMAN*
}

\begin{abstract}
Department of Biochemistry and Physiology, University of Reading, Whiteknights, P.O. Box 228, Reading RG6 2AJ, and "Public Health Laboratory Service, Toxoplasma Reference Laboratory, St George's Hospital, Blackshaw Road, London SW17 OOT
\end{abstract}

\begin{abstract}
Summary. A DNA-based assay has been developed for the detection of Toxoplasma gondii. The assay makes use of the polymerase chain reaction (PCR) to amplify part of the P30 gene on the parasite's DNA. Following gel electrophoresis, the amplified DNA can be detected either directly on the gel or by Southern hybridisation with radioactive or non-radioactive DNA probes. The assay has been used to detect the DNA from different isolates of $T$. gondii in a background of human or mouse DNA. Together with other information such as clinical data, CT scans and serology, the PCR assay should improve the diagnosis of toxoplasmosis in immunosuppressed and immunocompromised patients as well as in fetal tissues.
\end{abstract}

\section{Introduction}

Infection with Toxoplasma gondii is one of the most common parasitic infections of warm blooded animals including man. However, the only definitive hosts are domestic and wild cats. The incidence of human infection varies from country to country with about $20-40 \%$ of individuals infected in Great Britain, $50-60 \%$ in the USA and $80-90 \%$ in France. $^{1,2}$ In most human infections there are no signs or symptoms and there is no disease, although congenital toxoplasmosis may cause fetal death or result in severe disease in the infant and cerebral damage. ${ }^{3}$ Estimates of the incidence of congenital toxoplasmosis are $0.01 \%$ of live births in Great Britain $^{4}$ and $0 \cdot 1 \%$ in France. ${ }^{3}$ There is clear evidence that generalised toxoplasmosis may develop in patients on immunosuppressive therapy for malignant disease or for organ transplantation; this can involve the central nervous system and can result in death. ${ }^{5}$ Recently it has become increasingly evident that severe disseminated toxoplasmosis can be a life-threatening opportunist infection in patients with the acquired immunodeficiency syndrome (AIDS). ${ }^{6}$

The laboratory diagnosis of toxoplasmosis can be performed in several ways. ${ }^{4}$ These include the histological examination of lymph nodes (though many cases may be missed), the isolation of the parasite after inoculation of infection-free mice (this is time consuming, requiring 6-8 weeks, and may also fail to detect some cases), and several

Received 25 Aug. 1989; accepted 30 Oct. 1989. serological methods of which the dye test of Sabin and Feldman ${ }^{7}$ is the most commonly used. The latter test is difficult to perform and requires live toxoplasma (obtained by inoculation of infectionfree mice) and a supply of accessory factor obtained from normal human blood donors; the other serological tests are neither as sensitive nor as specific as the dye test. None of the methods currently used can be relied upon to give good results in patients with AIDS or other immunosuppressed patients. Furthermore, they do not offer a reliable diagnosis of toxoplasmosis in fetal specimens. Therefore, there is a need for quicker and more sensitive diagnostic procedures for the early diagnosis of toxoplasma infection in body fluids or biopsy tissues from immunosuppressed or immunocompromised patients and from fetuses.

A good alternative to serology may be the detection of the nucleic acids of a pathogen in clinical specimens. Nucleic acid preparations from infected tissues will contain the pathogen's nucleic acids, as well as those of the host; these may be detected and identified with pathogen-specific DNA or RNA probes. The application of recombinant DNA procedures has led to the development of several DNA probes for potential use in the detection of pathogens such as Neisseria gonorrhoeae in genital secretions, ${ }^{8}$ Plasmodium falciparum in blood, ${ }^{9}$ Leishmania spp., ${ }^{10}$ enterotoxigenic Escherichia coli in stools ${ }^{11}$ and cytomegalovirus in urine. ${ }^{12}$ The development of gene amplification procedures and, in particular, the polymerase chain reaction $(\mathrm{PCR})^{13}$ makes possible the detection of very small 
numbers of pathogens in clinical specimens. For example, the PCR has been used successfully to detect cytomegalovirus in marrow transplant recipients, ${ }^{14}$ hepatitis B virus in the serum of patients with chronic hepatatis ${ }^{15}$ and human papillomavirus in cervical smears. ${ }^{16}$

We are interested in developing a rapid and sensitive test for the diagnosis of $T$. gondii. Here we report the detection of $T$. gondii in different samples after amplification of part of the parasite's P30 gene ${ }^{17}$ by the PCR.

\section{Materials and methods}

\section{Preparation of toxoplasmas, inoculation of mice and isolation of DNA}

Twelve infection-free mice (MFl strain; A-L) were killed at 6-8 weeks of age and their heart blood and brains were removed; the sera were tested by the Sabin and Feldman dye test ${ }^{7}$ to confirm the absence of toxoplasma antibodies.

Each of $12 \mathrm{MF} 1$ mice $(\mathrm{O}-\mathrm{Z})$ at 6-8 weeks of age was inoculated intraperitoneally (i.p.) with $2.5 \times 10^{5} \mathrm{~T}$. gondii (RH strain) trophozoites. The mice were killed 3 days later and the heart blood, brains and peritoneal fluid were collected; sera were tested by the dye test ${ }^{7}$ to confirm the presence of toxoplasma antibodies.

The brains from six mice chronically infected with six different clinical isolates of toxoplasma were removed, ground with sterile pestles and mortars in the minimum volume of antibiotic medium and diluted to a concentration of $10-20$ cysts $/ \mathrm{ml}$ (determined by microscopic examination). MF1 mice were inoculated i.p. with $0.5 \mathrm{ml}$ of the cyst suspension; in the case of the Gleadle strain, which is more virulent than the rest, subcutaneous inoculation was used. Mice were killed 6 months later and the heart blood and brains were collected; all mice had positive dye test titres.

The preparation of DNA from $T$. gondii RH trophozoites was described previously. ${ }^{18}$ Human DNA from whole blood was isolated as described by Old. ${ }^{19}$ DNA from other human or mouse tissues was isolated in essentially the same way after homogenisation and washing of the tissue in phosphate-buffered saline (PBS; $10 \mathrm{~mm}$ sodium phosphate buffer, $\mathrm{pH} 7 \cdot 4,0 \cdot 13 \mathrm{M} \mathrm{NaCl}$ ). DNA samples were dissolved in water and stored at $-20^{\circ} \mathrm{C}$.

In many cases, crude DNA was used (see Results). Tissues under investigation were homogenised in $1 \mathrm{ml}$ of buffer A (20 mM Tris-HCl, pH 7.5, $1 \mathrm{mM} \mathrm{Na}_{2}$ EDTA) and centrifuged in a microfuge for $5 \mathrm{~min}$. The body fluids were also centrifuged. Cell pellets were resuspended in $1 \mathrm{ml}$ of buffer A and, after pelleting as above, they were resuspended in $150 \mu \mathrm{l}$ of water and incubated in a boiling water bath for $15 \mathrm{~min}$ before centrifugation in a microfuge for $10 \mathrm{~min}$. In the case of brain tissues, samples were mixed with a further $150 \mu \mathrm{l}$ of water, left at $4^{\circ} \mathrm{C}$ for $1 \mathrm{~h}$, boiled for $20 \mathrm{~min}$ and centrifuged for $15 \mathrm{~min}$. The supernates were used as a source of crude DNA.

Crude DNA was also prepared in the same way from Hammondia hammondii (a gift from Dr J. P. Dubey, U.S. Department of Agriculture, MD, USA), Cryptosporidium (a clinical isolate) and Eimeria vermiformis (a gift from Dr F. Nowell, Department of Pure and Applied Zoology, University of Reading); DNA samples from Giardia lamblia and G. muris were gifts from Miss D. C. Hay (Department of Pure and Applied Zoology, University of Reading).

\section{Amplification of toxoplasma DNA with the PCR}

The four oligonucleotides (oligos) used were all 20mers and were synthesised by Oswel DNA Service (Department of Chemistry, University of Edinburgh). Their sequences were based on the published sequence for the toxoplasma P30 gene $;{ }^{17}$ two of these (DS29 and DS38) were of the same sense as this sequence and the other two (DS30 and DS39) were of the opposite sense. Oligo DS29 (5'-TTGCCGCGCCCACACTGATG) corresponds to nucleotides $405-424$ of the P30 gene, oligo DS30 (5'-CGCGACACAAGCTGCGATAG) to nucleotides 1318-1299, oligo DS38 (5'-CGACAGCCGCGGTCATTCTC) to nucleotides 503-522 and oligo DS39 (5'-GCAACCAGTCAGCGTCGTCC) to nucleotides 1024-1005. When used in different combinations (DS29-DS30, DS29-DS39, DS38-DS39 and DS30-DS38) these oligos should result in the amplification of fragments of $T$. gondii DNA of $914,620,522$ and 815 bp respectively.

Amplification reactions (normally in a final volume of $50 \mu \mathrm{l})$ were performed with the thermostable Amplitaq ${ }^{\mathrm{TM}}$ recombinant Taq DNA polymerase (Perkin Elmer Cetus). In addition to the DNA to be amplified, each reaction mixture also contained $10 \mathrm{~mm}$ Tris- $\mathrm{HCl}, \mathrm{pH} 8 \cdot 3$, $50 \mathrm{mM} \mathrm{KCl}, 1.5 \mathrm{mM} \mathrm{MgCl}_{2}$, gelatin $0.01 \% \mathrm{w} / \mathrm{v}, 0.2 \mathrm{mM}$ each deoxynucleotide triphosphate, $0 \cdot 2 \mu \mathrm{M}$ each of the two oligos and 2.5 units of DNA polymerase; mineral oil $(50 \mu \mathrm{l})$ was added to each reaction to prevent evaporation. Several control reactions without any DNA were always carried out in parallel. The DNA in each reaction was initially melted by incubating at $95^{\circ} \mathrm{C}$ for $5 \mathrm{~min}$ before 30 cycles of amplification were performed with a programmable Dri-block (Techne, Cambridge); each amplification cycle consisted of incubations at $95^{\circ} \mathrm{C}$ for $1 \mathrm{~min}$, $60^{\circ} \mathrm{C}$ for $1 \mathrm{~min}$ and $74^{\circ} \mathrm{C}$ for $3 \mathrm{~min}$. At the end of the 30 cycles of amplification, the reactions were incubated at $25^{\circ} \mathrm{C}$ for $5 \mathrm{~min}$. When required, sequential amplifications were performed with $5 \mu \mathrm{l}$ of DNA from the first amplification reaction.

\section{Gel electrophoresis of DNA and Southern hybridisation}

Electrophoresis and, where necessary, isolation of DNA fragments from agarose gels were performed as described previously. ${ }^{20}$ 
Southern blotting on to nylon Hybond- $\mathrm{N}^{\mathrm{TM}}$ membranes was performed as recommended by the supplier of the membrane (Amersham International, Amersham, Bucks). In some cases, the amplified DNA was applied to the nylon membrane by either a Hybri-dot ${ }^{\mathrm{TM}}$ or a Hybri-slot $^{\mathrm{TM}}$ apparatus (Gibco-BRL).

DNA-DNA hybridisations were performed as described earlier. ${ }^{18}$ The DNA probe was the 522-bp fragment generated after amplification of toxoplasma DNA with oligos DS38 and DS39. DNA probes were either radiolabelled with ${ }^{32} \mathrm{P}$ to a specific activity of $10^{9} \mathrm{dpm} / \mu \mathrm{g}$ of DNA with the Multiprime ${ }^{\text {TM }}$ system (Amersham International) or biotin-labelled with a photobiotin labelling kit as described by the supplier (Gibco-BRL, Paisley); in the former case, hybrids were detected by autoradiography and in the latter case by the bluGENE $^{\circledR}$ system (Gibco-BRL) as described by the supplier.

\section{Results}

\section{Amplification of toxoplasma DNA}

Reactions containing different amounts of $T$. gondii (strain RH) DNA, with or without human DNA $\left(5 \mu \mathrm{g}\right.$, which corresponds to $c .1 .5 \times 10^{6}$ leucocytes), were used to establish the sensitivity of the amplification reactions. As shown in fig. 1a, after amplification (30 cycles with oligos DS29 and DS30), electrophoresis and staining of the gels with ethidium bromide, a 914-bp DNA fragment was visible in those reactions containing as little as $10 \mathrm{pg}$ of toxoplasma DNA. This band, which corresponds to nucleotides 405-1318 of the toxoplasma P30 gene, was visible only in those reactions which did not contain any human DNA. In reactions containing human DNA this fragment was obscured by a smear of DNA fragments.

Identical levels of detection (results not shown) were obtained when the amplification reactions contained different pairs of oligos instead of DS29 and DS30. In such cases the size of the amplified DNA fragments was 815 bp with DS30-DS38, 620 bp with DS29-DS39 and 522 bp with DS38DS39; these DNA fragments were also obscured by a smear of DNA in those reactions containing human DNA.

However, as shown in figs. $1 \mathrm{~b}$ and $1 \mathrm{c}$, this problem can be eliminated after Southern hybridisation to either a radioactive or a biotinylated DNA probe corresponding to nucleotides 503-1024 of the toxoplasma P30 gene. Furthermore, after hybridisation, the amount of toxoplasma DNA that could be detected was as low as $0.5 \mathrm{pg}$; the radioactive and biotinylated probes gave essentially identical results.
Dot hybridisations with a radiolabelled DNA probe were also performed and the results obtained (not shown) were identical to those from the Southern hybridisations. The specificity of the amplification reaction was examined with DNA samples isolated from related parasites. Amplification products were not obtained with any of the DNA preparations from Hammondia, Cryptosporidium, Giardia or Eimeria.

\section{Sequential amplification of toxoplasma $D N A$}

After a 30-cycle amplification with oligos DS29 and DS30, 5- $\mu$ l samples were amplified for a further 30 cycles with either the same or a different pair of oligos. Apart from the difference in the size of the amplified fragments, all pairs of oligos gave identical results. As shown in fig. 2, the lowest amount of toxoplasma DNA detectable after sequential amplification (first with DS29 and DS30 and then with DS38 and DS39) was $0.05 \mathrm{pg}$. The results also show that the 522-bp DNA fragment was visible both in the presence and in the absence of contaminating human DNA.

\section{Detection of $T$. gondii in mouse tissues}

The sequential amplification reactions described above were used to detect the presence of $T$. gondii in tissues and body fluids from 12 mice infected with the RH strain of $T$. gondii and from 12 uninfected mice $(\mathrm{O}-\mathrm{Z}$ and $\mathrm{A}-\mathrm{L}$ respectively). Samples $(15 \mu \mathrm{l})$ of crude DNA preparations from the heart blood and the brains of all the mice, and from the peritoneal fluids of the infected mice, were amplified and examined after electrophoresis. The crude DNA preparations from the brains and heart blood of the 12 uninfected mice did not produce any amplification of toxoplasma DNA. In the case of the 12 infected mice, amplification was obtained with the DNA preparations from 11 peritoneal fluids (the exception being that of mouse $X$ ) and one heart blood (that of mouse $\mathrm{Z}$ ); amplification was not obtained with the DNA from any of the brains. Some of the results are shown in fig. 3 . Identical results were also obtained when purified DNA instead of crude DNA preparations were used.

Crude DNA preparations from the heart blood and from the brains of mice infected with different isolates of $T$. gondii were also screened by sequential amplifications. The results shown in the table indicate that these isolates are also detectable by this double PCR assay; detection was possible in most of the brains but not in any of the heart blood samples. 


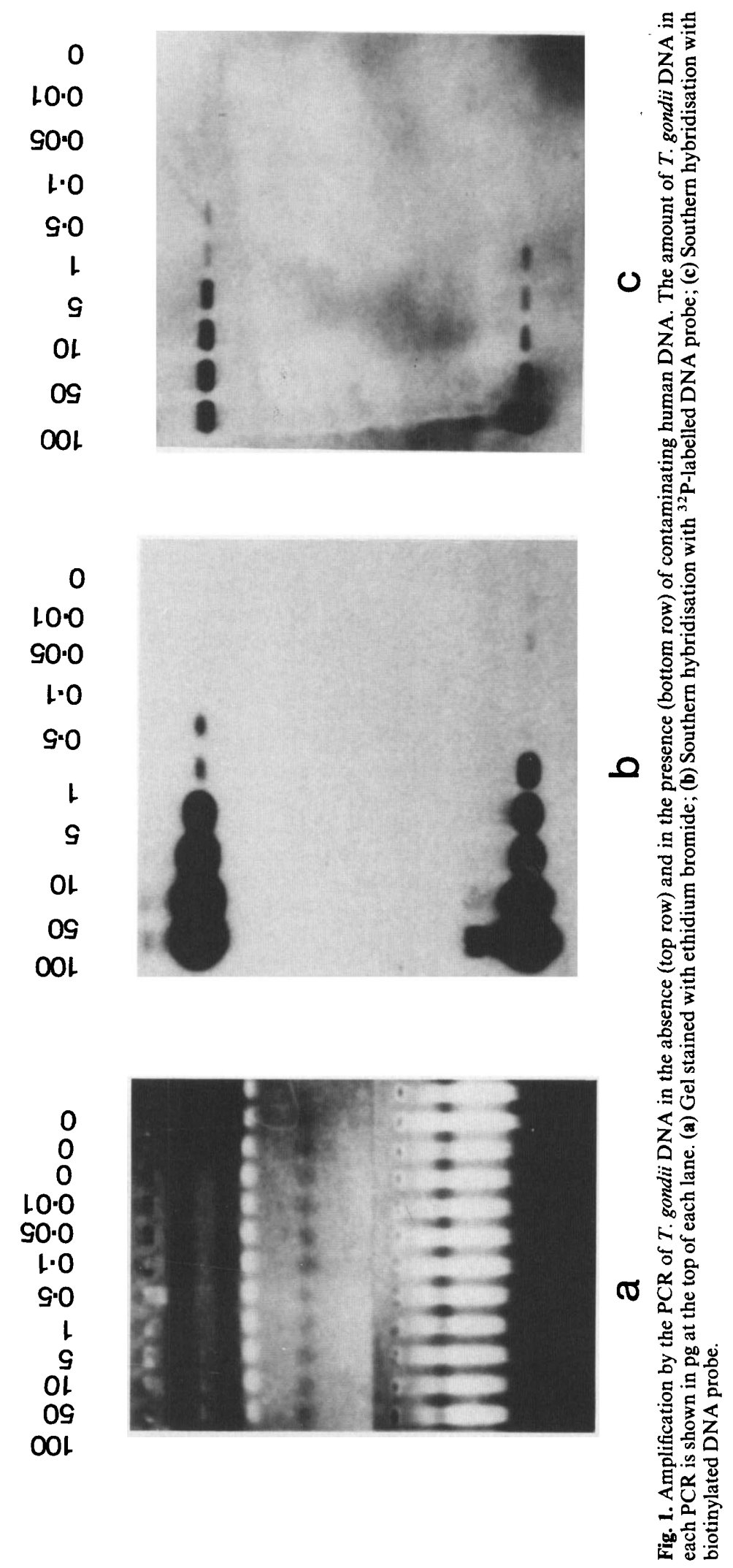




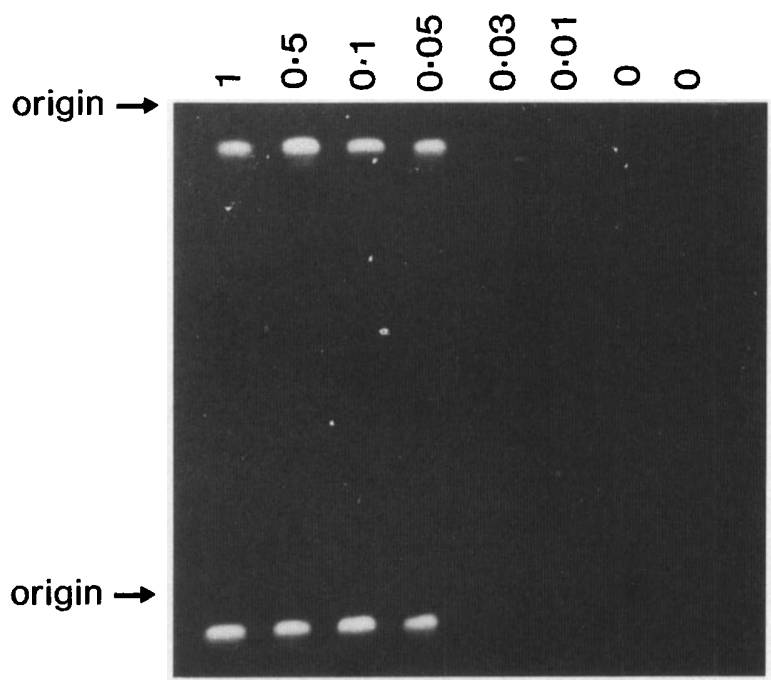

Fig. 2. Detection of $T$. gondii DNA after sequential amplification by PCR and gel electrophoresis. The top row of samples did not contain human DNA and the bottom row contained $5 \mu \mathrm{g}$ of human DNA. The amount of $T$. gondii DNA present in each sample is shown in pg at the top of each lane.

\section{Discussion}

Recent evidence suggests that the tests currently used for the detection of toxoplasmosis suffer from serious deficiencies, especially in cases of immunosuppressed and immunocompromised individuals. ${ }^{5,6}$ In an effort to overcome these deficiencies we have used a molecular biological approach to detect the parasite's DNA in infected tissues. Similar approaches have been used to detect several bacterial,,$^{8,11}$ viral $^{12,14-16}$ and protozoan ${ }^{9,10}$ parasites.

The application of recombinant DNA procedures in studies on toxoplasma has resulted in the cloning of a number of characterised or, as yet, uncharacterised $T$. gondii DNA fragments. ${ }^{17,18} \mathrm{We}$ have previously used some uncharacterised cloned DNA fragments and dot hybridisation assays to detect $T$. gondii DNA but the assay was relatively insensitive as it could not detect DNA corresponding to fewer than $10^{5} T$. gondii trophozoites. ${ }^{18}$ However, the sensitivity of such DNA assays can be improved dramatically by the application of gene amplification with the PCR. ${ }^{13}$ In this study we have used the information on the structure of the gene encoding the major surface antigen P30 of $T$. gondii ${ }^{17}$ to develop a PCR assay specific for the parasite.

The results indicate that when DNA purified from $T$. gondii $\mathrm{RH}$ trophozoites was amplified under the conditions described in the Materials and methods in a 30-cycle PCR with the two 5' oligos (DS29 and DS38) and two 3' oligos (DS30 and DS39) in different paired combinations, the $T$. gondii DNA was amplified with good specificity to generate DNA fragments of the expected sizes. When amplified DNA was visualised in ethidium bromide-stained gels (fig. 1a) the expected DNA fragments were not observed in reactions which contained human DNA because of the presence of smears of DNA fragments; these smears presumably resulted from self-priming and amplification

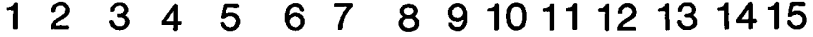

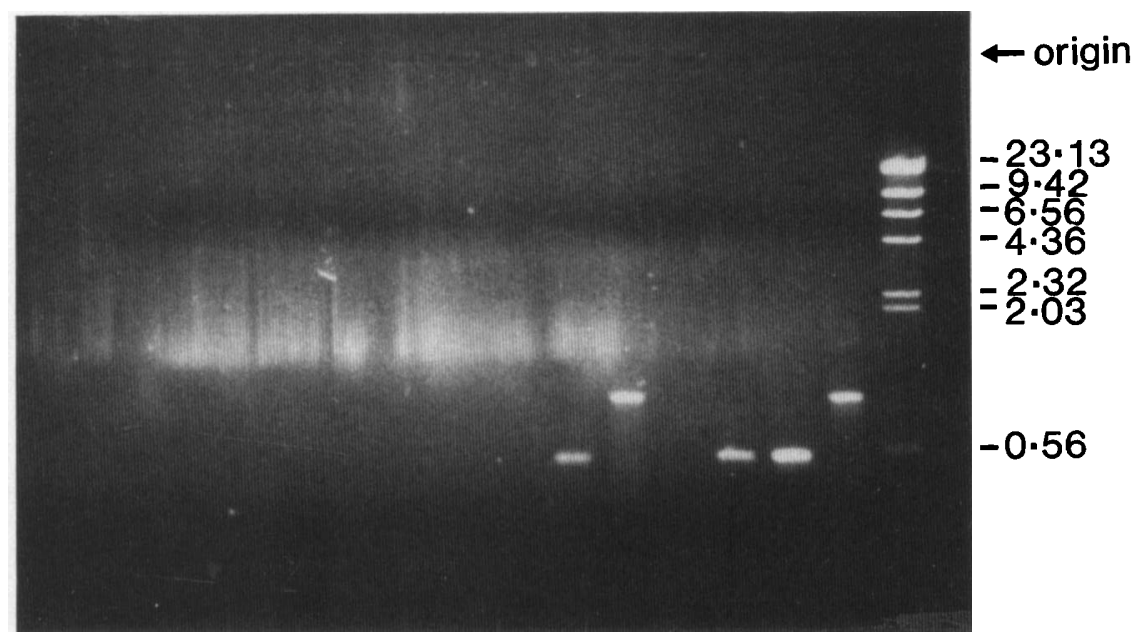

Fig. 3. Detection of $T$. gondii DNA in crude DNA samples from different tissues of one uninfected (lanes 1 and 2) and three RHinfected mice (lanes 3-6,7-10 and 11-14 represent DNA samples from mice X, Y and Z respectively). DNA samples in lanes 1, 3, 7 and 11 were from brain, those in lanes $2,4,8$ and 12 from heart blood and those in lanes 5, 6, 9, 10, 13 and 14 from peritoneal fluid. All samples were from the second PCR except those in lanes 6,10 and 14 which were from the first PCR. Lane 15 shows bacteriophage $\lambda$ DNA cleaved with HindIII; the length of each DNA fragment is shown in kb. 
Table. Detection of $T$. gondii DNA in the brains and heart blood of different isolates of toxoplasma

\begin{tabular}{|c|c|c|c|}
\hline \multirow{2}{*}{\multicolumn{2}{|c|}{$\begin{array}{c}\text { Mouse infected with } \\
\text { T. gondii strain }\end{array}$}} & \multicolumn{2}{|c|}{ Detection of $T$. gondii DNA in } \\
\hline & & brain & heart blood \\
\hline & + & - \\
\hline Gleadle 105 & $104-1$ & + & - \\
\hline & $104-2$ & + & - \\
\hline \multirow{3}{*}{ Tree } & $150-2$ & + & - \\
\hline & $150-1$ & + & - \\
\hline & $72-5 \mathrm{C}$ & + & - \\
\hline \multicolumn{2}{|c|}{ Saunders $22-1$} & + & - \\
\hline \multicolumn{2}{|r|}{$22-2$} & + & - \\
\hline \multicolumn{2}{|c|}{$21-1$} & - & - \\
\hline \multicolumn{2}{|c|}{$21-2$} & + & - \\
\hline \multirow{2}{*}{\multicolumn{2}{|c|}{$\begin{array}{r}21-3 \\
21-4\end{array}$}} & - & - \\
\hline & & + & - \\
\hline \multirow{10}{*}{ Cotterell } & A & - & - \\
\hline & B & + & - \\
\hline & $\mathrm{C}$ & + & - \\
\hline & D & + & - \\
\hline & 1 & + & - \\
\hline & 2 & + & - \\
\hline & 3 & + & - \\
\hline & 4 & - & - \\
\hline & 5 & + & - \\
\hline & 6 & + & - \\
\hline \multirow[t]{5}{*}{ El Araby } & 7 & + & - \\
\hline & 8 & + & - \\
\hline & 9 & + & - \\
\hline & 10 & - & - \\
\hline & 11 & - & - \\
\hline \multirow[t]{2}{*}{ Jones } & 1 & - & - \\
\hline & 2 & - & - \\
\hline
\end{tabular}

,$+ T$. gondii DNA detected by amplification;,$- T$. gondii DNA not detected.

of the human DNA. To overcome this problem, Southern hybridisations with either radiolabelled or biotinylated DNA probes were performed. The results (figs. $1 \mathrm{~b}$ and $\mathrm{c}$ ) demonstrated that the $T$. gondii-specific band of amplified DNA could be detected by the DNA probe both in the presence and in the absence of contaminating human DNA; the minimum amount of $T$. gondii DNA that could be detected was $0.5 \mathrm{pg}$.

Because the time required for the PCR-hybridisation assay is considerable (at least 2 days), we have attempted to reduce this by two sequential PCRs with the second PCR performed on a small sample from the first; the second amplification reaction was performed with different combinations of oligos with essentially identical results. This procedure allowed the detection of as little as $0.05 \mathrm{pg}$ of $T$. gondii DNA even in the presence of contaminating human DNA; this amount of $T$. gondii DNA probably represents just a single organism although the exact size of the genome is not known yet. Furthermore, this assay was not found to give false positive results with related parasites; this is of particular interest in the case of Hammondia hammondii which shows serological cross reactivity with $T$. gondii. ${ }^{21}$

The double PCR assay was used to detect $T$. gondii DNA in tissues (brains) and body fluids (heart blood and peritoneal fluid) from uninfected and from $T$. gondii $\mathrm{RH}$-infected mice. The results show that amplification was obtained only with DNA preparations from the infected mice; the desired amplification product was seen with all but one of the peritoneal fluids (that from mouse $\mathrm{X}$ ) and with only one of the 12 samples of heart blood (mouse Z). Furthermore, with the peritoneal fluid samples it was possible to detect the infection even after the first amplification (fig. 3). It is possible that the negative result with the peritoneal fluid from mouse $\mathrm{X}$ resulted from the failure to establish infection after inoculation. Also, it appears that parasitaemia in $\mathrm{RH}$-infected mice is not normally established within 3 days of inoculation but mouse $\mathrm{Z}$, which shows parasitaemia, may represent a more advanced stage of infection.

The suitability of this PCR assay for detecting isolates of $T$. gondii other than the RH strain was tested with tissues from mice infected with different clinical isolates. These isolates are known to be less virulent than the RH strain for mice and persistent parasitaemia is not a normal consequence of infection; the results in the table are in full agreement with this. It is possible that the absence of positive results with some of the brains was due to the failure of the inoculated material to establish an infection.

The results presented here suggest that it is possible to detect $T$. gondii in body tissues and fluids by the PCR with specific oligonucleotide primers. Indeed, we have used the procedures described here to examine several clinical samples including the products of conception and brain biopsies from AIDS patients (unpublished results). The results so far are very encouraging and suggest that in the not too distant future the PCR assay may be used routinely to complement serology for the diagnosis of toxoplasmosis.

We thank Dr D. G. Fleck (former Director of the Toxoplasma Reference Laboratory, St George's Hospital) for advice, helpful discussion and encouragement during the course of these studies, and Dr R. Woods (Department of Biochemistry and Physiology, University of Reading) for useful comments and technical advice. This work was supported by a grant from the Medical Research Council. 


\section{REFERENCES}

1. Feldman H A. Toxoplasmosis: an overview. Bull NY Acad Med 1974; 50: 110-127.

2. Beattie C P. The ecology of toxoplasmosis. Ecol Dis 1982; 1 : $13-20$

3. Desmonts G, Couvreur J. Toxoplasmosis in pregnancy and its transmission to the fetus. Bull NY Acad Med 1974; 50: $146-149$.

4. Fleck D G, Kwantes W. The laboratory diagnosis of toxoplasmosis. Public Health Laboratory Service Monograph Series 13, London, HMSO. 1980.

5. Frenkel J K, Amare M, Larsen $\mathbf{W}$. Immune competence in a patient with Hodgkin's disease and relapsing toxoplasmosis. Infection 1978; 6: 84-91.

6. Holliman R E. Toxoplasmosis and the acquired immune deficiency syndrome. $J$ Infect $1988 ; 16: 121-128$.

7. Sabin A B, Feldman H A. Dyes as microchemical indicators of a new immunity phenomenon affecting a protozoan parasite (Toxoplasma). Science 1948; 108: 660-663.

8. Totten P A, Holmes K K, Handsfield H H, Knapp J S, Perine P L, Falkow S. DNA hybridization technique for the detection of Neisseria gonorrhoeae in men with urethritis. J Infect Dis $1983 ; 148: 462-471$.

9. Franzen L, Westin G, Shabo R et al. Analysis of clinical specimens by hybridisation with probe containing repetitive DNA from Plasmodium falciparum: a novel approach to malaria diagnosis. Lancet 1984 ; 1 : 525527

10. Barker D C, Gibson L J, Kennedy W P K, Nasser A A A $A$, Williams $\mathrm{R} \mathrm{H}$. The potential of using recombinant DNA species-specific probes for the identification of tropical Leishmania. Parasitology 1986; 92: S139-S174.

11. Moseley S L, Echeverria P, Seriwatana J et al. Identification of enterotoxigenic Escherichia coli by colony hybridization using three enterotoxin gene probes. $J$ Infect Dis $1982 ; 145: 863-869$.
12. Chou S, Merigan T C. Rapid detection and quantitation of human cytomegalovirus in urine through DNA hybridization. New Engl J Med 1983; 308: 921-925.

13. Saiki R K, Scharf S, Faloona Fet al. Enzymatic amplification of $\beta$-globin genomic sequences and restriction site analysis for diagnosis of sickle cell anemia. Science 1985; 230 : $1350-1354$.

14. Cassol S A, Poon M-C, Pal R et al. Primer-mediated enzymatic amplification of cytomegalovirus (CMV) DNA. Application to the early diagnosis of CMV infection in marrow transplant recipients. $J$ Clin Invest 1989; 83: 1109-1115.

15. Kaneko S, Miller R H, Feinstone S M et al. Detection of serum hepatitis $B$ virus DNA in patients with chronic hepatitis using the polymerase chain reaction assay. Proc Natl Acad Sci USA 1989; 86: 312-316.

16. Young L S, Bevan I S, Johnson M A et al. The polymerase chain reaction: a new epidimiological tool for investigating cervical human papillomavirus infection. $\mathrm{Br}$ Med J 1989; 298: 14-18.

17. Burg J L, Perelman D, Kasper L H, Ware P L, Boothroyd J C. Molecular analysis of the gene encoding the major surface antigen of Toxoplasma gondii. J Immunol 1988; 141 : 3584-3591.

18. Savva D. Isolation of a potential DNA probe for Toxoplasma gondii. Microbios 1989; 58: 165-172.

19. Old J M. Fetal DNA analysis. In: Davies K E (ed) Human genetic diseases: a practical approach. Oxford, IRL. 1986: $1-17$.

20. Savva D, Mandelstam J. Cloning of the Bacillus subtilis spoIIA and spoVA loci in phage $\phi 105 \mathrm{DI}: 1 \mathrm{t}$. J Gen Microbiol 1984; 130: 2137-2145.

21. Munday B L, Dubey J P. Serological cross-reactivity between Hammondia hammondi and Toxoplasma gondii in experimentally inoculated sheep. Aust Vet $J$ 1986; 63: 344345. 